\title{
Diurnal patterns of ambient temperature but not precipitation influence incubation behavior in Great Tits
}

\author{
Eva Maria Schöll ${ }^{1}\left[\right.$ · Manuel Polo Aparisi ${ }^{1} \cdot$ Sabine Marlene Hille $^{1}[(]$
}

Received: 29 May 2019 / Revised: 14 November 2019 / Accepted: 18 November 2019 / Published online: 26 November 2019

(c) The Author(s) 2019

\begin{abstract}
Environmental conditions affect incubation behavior, but whilst the effect of ambient temperature is studied and still controversially discussed, the role of precipitation is unknown. Here, we analyzed the effect of local ambient temperature and precipitation on incubation behavior of female Great Tits (Parus major) and accounted for diurnal patterns of weather conditions. We monitored the incubation behavior of females using temperature data loggers, thus identifying periods of staying inside nest boxes incubating, and leaving nest boxes (off-bout). In total, 685 single off-bouts were analyzed between the first 8 days of incubation directly after clutches were completed. Our study showed that whilst precipitation had no effect on incubation behavior, number and duration of off-bouts were negatively related to ambient temperature, which varied throughout the day. We showed that females took longer off-bouts during low-temperature early mornings, which may result from the need to forage after fasting during the night. Thus, foraging in the early morning seemed to outcompete energy requirements during these cold temperature periods. In addition, females spent less time off the nest as incubation progressed. Our results emphasize that patterns of incubation behavior cannot be understood without taking into account varying temperature conditions throughout the day.
\end{abstract}

Keywords Data logger $\cdot$ Environmental conditions $\cdot$ Female behavior $\cdot$ Nest boxes $\cdot$ Off-bout $\cdot$ Parus major

\section{Zusammenfassung}

Tagesschwankungen der Umgebungstemperatur, nicht aber des Niederschlages, beeinflussen das Inkubationsverhalten von Kohlmeisen

Umweltbedingungen beeinflussen das Inkubationsverhalten. Während der Einfluss der Umgebungstemperatur untersucht, aber noch immer kontrovers diskutiert wird, ist die Rolle des Niederschlags unbekannt. In dieser Studie analysierten wir den Einfluss von lokalen Temperatur- und Niederschlagsbedingungen auf das Inkubationsverhalten weiblicher Kohlmeisen (Parus major) und berücksichtigten dabei tageszeitliche Rhythmen der Wetterbedingungen. Wir untersuchten das Inkubationsverhalten von Weibchen mithilfe von Temperaturdatenloggern und identifizierten so Zeiträume, in denen sie sich im Nistkasten aufhielten oder ihn verließen (Off-Bout). Insgesamt wurden 685 einzelne Off-Bouts innerhalb der ersten acht Tage der Inkubation analysiert. Unsere Studie zeigt, dass Niederschläge zwar keinen Einfluss auf das Inkubationsverhalten hatten, aber die Anzahl und Dauer der Off-Bouts in einem negativen Zusammenhang mit der Umgebungstemperatur stand, welche im Laufe des Tages variierte. Die Weibchen unternahmen während der frühen Morgenstunden bei niedrigen

Communicated by S. Bouwhuis.

Electronic supplementary material The online version of this article (https://doi.org/10.1007/s10336-019-01737-9) contains supplementary material, which is available to authorized users.

Eva Maria Schöll

eva.schoell@boku.ac.at

1 Institute of Wildlife Biology and Game Management, University of Natural Resources and Life Sciences Vienna,

Gregor-Mendel Straße 33, 1180 Vienna, Austria 
Temperaturen längere Ausflüge. Womöglich müssen die Weibchen nach einer Nacht ohne Nahrungsaufnahme gerade in den frühen Morgenstunden nach Futter suchen. Die Nahrungssuche am frühen Morgen könnte durchaus den Energiebedarf während dieser kalten Temperaturperioden ausgleichen. Darüber hinaus verbrachten die Weibchen mit fortschreitender Inkubation weniger Zeit außerhalb des Nests. Unsere Ergebnisse verdeutlichen, dass Muster im Inkubationsverhalten nicht vollständig verstanden werden können, ohne die unterschiedlichen Temperaturverhältnisse während des Tages zu berücksichtigen.

\section{Introduction}

A variety of factors are assumed to affect incubation behavior, e.g., stage of incubation (Álvarez and Barba 2014b; Basso and Richner 2015), clutch size (Thomson et al. 1998), predation risk (Conway and Martin 2000b), male feeding behavior (Bambini et al. 2019), phenology (Cresswell and McCleery 2003; Simmonds et al. 2017) and weather conditions. Birds that employ uniparental incubation face a trade-off between maintaining egg temperature and their own body condition during incubation period, as they have to leave the nest repeatedly (Kluijver 1950) to avoid depleting stored resources (Reid et al. 2002). In temperate regions, unattended eggs cool down during these off-bouts since ambient temperatures are usually lower than the appropriate temperature for optimal embryo development (Drent 1975). Embryos may endure short periods with sub-optimal conditions, but temperature should not fall below $24-26^{\circ} \mathrm{C}$, because too low temperature can result in suboptimal development, whereas high temperatures above $40.5{ }^{\circ} \mathrm{C}$ can be lethal (Drent 1975; DuRant et al. 2013). Therefore, ambient temperature has a strong impact on the decision-making of incubating birds (Deeming 2002). Re-warming eggs after taking an off-bout is energetically more costly than maintaining eggs at high temperatures (Vleck 1981; Williams 1996). The energy demand of heating eggs is dependent on ambient temperature and less energy is needed if ambient temperature is close to an optimal incubation temperature between 36 and $40{ }^{\circ} \mathrm{C}$ (Biebach 1986; Conway and Martin 2000a; DuRant et al. 2013). Thus, females should increase nest attendance, if the temperature is low (see also BuenoEnciso et al. 2017), so that eggs do not cool down repeatedly. However, to cope with high energetic requirements during low-temperature periods, females have to take off-bouts to forage (Moiron et al. 2018).

As ambient temperature follows a diurnal rhythm, incubation behavior should vary throughout the day, but the effect of diurnal patterns on number and duration of off-bouts is not yet studied in detail (Conway and Martin 2000a; Boulton et al. 2010). First indications for variation in incubation behavior throughout the day were found in the studies of Prinzinger (1978) and Joyce et al. (2001), who hypothesized that these could be related to diurnal temperature cycles (but see Álvarez and Barba 2014c).
Incubation patterns are assumed to be affected by precipitation as well, as birds may stay at nests to shield their eggs during rainfall (Skutch 1962). In addition, open-nesting birds usually show higher nest attentiveness during rainy episodes (Kovařík et al. 2009). Birds breeding in open nests might experience greater exposure to weather conditions than hole-breeders (Hansell and Deeming 2002; Martin et al. 2017). On the other hand, birds breeding in natural holes or cavities could avoid getting wet by remaining within their nests while it rains, but even nests of hole-nesting birds can become soaked (Wesolowski et al. 2002). Coe et al. (2015) found in Tree Swallows (Tachycineta bicolor) that females spent less time off the nest, if precipitation occurred. In contrast, Basso and Richner (2015) tested how precipitation affects incubation behavior of female Great Tits (Parus major), but found no effect of precipitation on the number and duration of off-bouts. Thus, the effect of precipitation on incubation patterns is not yet clarified. In addition, as frequency and intensity of daily precipitation also follow a diurnal cycle (Dai et al. 2007), females should adapt their incubation behavior to these precipitation patterns and stay in nest boxes during rainy periods to seek out shelter. They should avoid water penetration of the plumage, since birds need a lot of energy to compensate for heat loss if their feathers are wet (Wilson et al. 2004).

The aim of this paper is to study the effects of diurnal cycles in ambient temperature and precipitation on incubation behavior, as the effect of diurnal weather conditions on number and duration of off-bouts has not been studied in detail so far. Our model species is the Great Tit, a uniparental incubator. Thus, only females are incubating the eggs (Kluijver 1950). In this study, we have two specific hypotheses. The first is that female Great Tits will adapt their incubation behavior to ambient temperature, by reducing the number and/or duration of off-bouts during low-temperature periods. This would suggest cooling of eggs and energetic considerations are key drivers of female incubation behavior. The second hypothesis is that females will stay in nest boxes during rainy periods to seek out shelter. Since ambient temperature and precipitation follow a diurnal cycle, we expect that incubation patterns vary throughout the daytime. To explore incubation behavior of female Great Tits, we used small data loggers which detected differences in temperature within the nests indicating if females sit on the clutch or not (on- and off-bout). 


\section{Materials and methods}

\section{Study area}

Field work was carried out in a mountainous forest dominated by Beech (Fagus sylvatica) in Lower Austria $\left(48^{\circ} 03^{\prime}\right.$ $\left.\mathrm{N}, 15^{\circ} 55^{\prime} \mathrm{E}\right)$ in the year 2015 . The study was conducted on a Great Tit population breeding in wooden next boxes, which were evenly distributed along an altitudinal gradient (515-867 $\mathrm{m}$ above sea level). We inspected nest boxes every 4-6 days (starting in the end of March) to determine date of clutch initiation. Since Great Tits usually lay one egg per day (Perrins 1965), we could calculate date of clutch initiation for each nest.

\section{Obtaining regional weather parameters}

To get an overview of weather conditions and diurnal cycles, data on regional ambient temperature $\left({ }^{\circ} \mathrm{C}\right)$ and precipitation $(\mathrm{mm} / \mathrm{h})$ were obtained from a weather station located within the study site (Office of the Provincial Government of Lower Austria, Hydrology and Geoinformation, official webpage: www.noe.gv.at, temporal resolution: every $15 \mathrm{~min})$. During the study period, regional ambient temperature measured at the meteorological station varied between 2.2 and $22.5^{\circ} \mathrm{C}$. Regional ambient temperature was lowest in the early morning at dawn, rose until noon and reached the maximum in

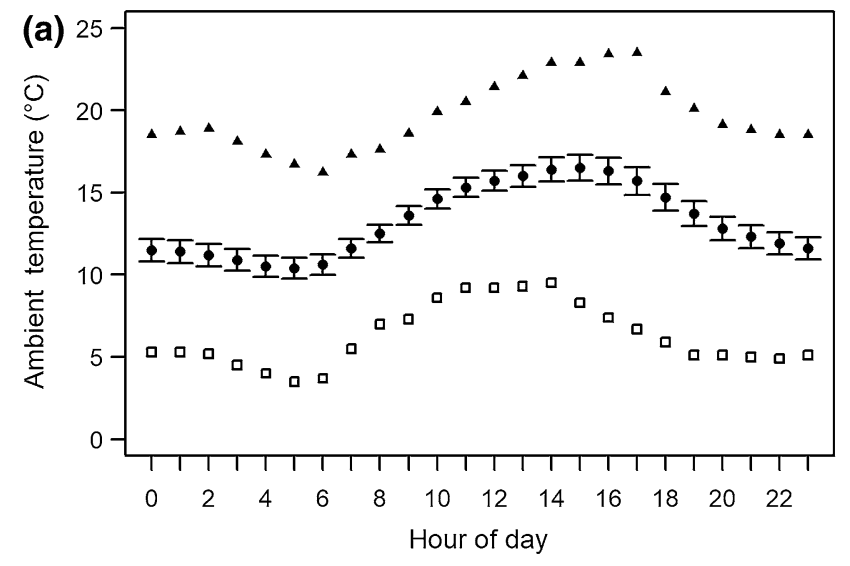

Fig. 1 Regional weather conditions measured throughout the study period from 26 April 2015 until 18 May 2015 at a central meteorological station. a Regional ambient temperature $\left[{ }^{\circ} \mathrm{C}\right.$, mean $\pm \mathrm{SE}$, the early afternoon (see Fig. 1a). However, for our statistical analyses, ambient temperature was measured in a finer resolution on each nest box (see below). Regional precipitation varied between 0 and $14.1 \mathrm{~mm} / \mathrm{h}$. Morning rain was less frequent than afternoon rain (see Fig. 1b; Yaqub et al. 2010). For analyses, regional precipitation data were used from the local weather station (see Table 1).

\section{Breeding data collection}

After egg detection, nest boxes were checked daily to determine clutch sizes. After clutches were completed, we measured length and width of each egg to the nearest $0.1 \mathrm{~mm}$ to calculate total egg volume of each clutch (Tatum 1975), since clutch volume affects cooling rates (Reid et al. 2000). To limit the risk of nest desertion, we trapped females only during the nestling period. Females were individually ringed and aged, and body mass was measured (to the nearest $0.1 \mathrm{~g}$ ). Mean \pm standard deviation (SD) is shown where appropriate.

\section{Assessing incubation behavior}

To study incubation behavior, we installed iButton data loggers (DS1922L, Maxim Integrated, San Jose, USA) in 34 nest boxes to record temperature. Previous studies verified temperature measurements using camera recordings by showing that off-bouts correlate with female nest attendance

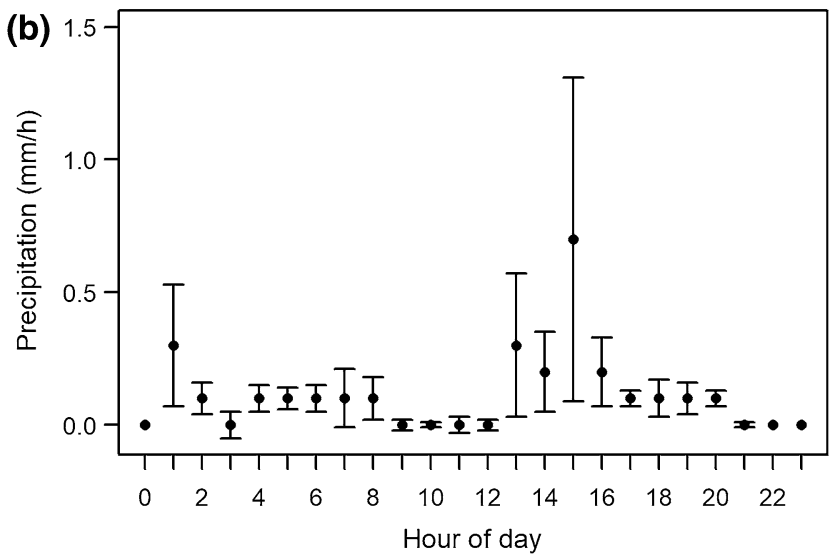

minimum (square) and maximum (triangle)] and $\mathbf{b}$ regional amount of precipitation $(\mathrm{mm}$, mean $\pm \mathrm{SE})$
Table 1 Descriptive statistics of weather variables measured between civil dawn and dusk (mean, standard error SE, range)

\begin{tabular}{lcl}
\hline Variables & Mean \pm SE & Minimum-maximum \\
\hline Average daily local ambient temperature $\left({ }^{\circ} \mathrm{C}\right)$ & $13.75 \pm 0.31$ & $8.97-20.69$ \\
Average local ambient temperature during off-bouts $\left({ }^{\circ} \mathrm{C}\right)$ & $13.05 \pm 0.14$ & $2.85-25.10$ \\
Sum of regional precipitation $(\mathrm{mm})$ per day & $2.18 \pm 0.43$ & $0-24.10$ \\
\hline
\end{tabular}


(Joyce et al. 2001; Amininasab et al. 2016; Bueno-Enciso et al. 2017). Data loggers were inserted during the egg-laying period, when 7-10 eggs were already laid. At the moment of logger insertion, eggs were still cold, thereby indicating that incubation had not started yet. We fixed loggers using wire to avoid females removing them (see Electronic Supplementary Material). Temperature loggers were placed underneath the eggs within the nest lining layer, because our preliminary studies had shown that eggs can break during the incubation period, if loggers are placed among them. Therefore, we have not measured exact incubation temperature, but we can analyze female incubation as a pattern resulting from the temperature in the nest that varies due to female activity, either sitting on the clutch or not (on- and off-bout). To avoid replacing or interrupting measurement loggers and disturbing females during incubation, we inserted three loggers at a time. These loggers were programmed to record temperature at staggered intervals. Every logger measured temperature for five consecutive days, in total covering a maximum duration of 15 days. Temperature in the nest cup was recorded every $60 \mathrm{~s}$ to the nearest $0.5^{\circ} \mathrm{C}$.

After 15 days, we removed the loggers and analyzed temperature data. We used a file converter software program (Rhythm, see Cooper and Mills 2005) which pre-selected off-bouts, based on the following criteria: off-bouts were categorized as a minimum temperature drop of at least $1.5{ }^{\circ} \mathrm{C}$ for a minimum duration of $3 \mathrm{~min}$. We assume that our temperature measurements every $60 \mathrm{~s}$ and the preliminary settings to detect off-bouts are accurate to study incubation behavior, since average off-bout duration of Great Tits breeding in Europe lasts between 7 and 12 min (see review table of Álvarez and Barba 2014c). Temperature profiles and off-bouts were confirmed visually using the software Raven, a product of the Bioacoustics Research Program at Cornell Laboratory of Ornithology. We were aware that incubation might have begun prior to clutch completion (Cresswell and McCleery 2003; Stenning 2008; Álvarez and Barba 2014b; Simmonds et al. 2017), but we had to standardize the data before analyses. Thus, we defined the onset of incubation as the first day after the last egg was laid (clutch completion, see also Kluijver 1950).

From the 34 nests with temperature loggers placed and retrieved, three nests were removed from analyses because they were abandoned; three nests were removed because they were predated during incubation; and a further 15 nests were removed because loggers were deeply buried inside the nesting material and did not measure temperature adequately. We therefore analyzed data from the remaining 13 nests. Since loggers were inserted during the egg-laying period and before incubation had begun, the number of days with recorded temperature profiles during the incubation period varied for each of the 13 nests. Therefore, temperature measurements did not cover the whole incubation period of Great
Tits, which usually lasts for $12-15$ days (Glutz von Blotzheim and Bauer 1993). Instead, incubation behavior was analyzed within the first 8 days of incubation after clutches were completed in our study site [between day 1 and day 8: 8 nests, between day 1 and day 7: 3 nests, between day 2 and day 8: 2 nests, $N$ (total) $=99$ days .

On each nest box, ambient temperature was measured (accuracy: $0.5^{\circ} \mathrm{C}$ ) to link local ambient temperature to incubation temperature profiles (hereinafter "local ambient temperature"). Temperature loggers were fixed underneath nest boxes using a mesh to avoid direct solar irradiation at any daytime. Great Tits usually use the time period between sunrise and sunset for daily activities (Kluijver 1950); thus, we analyzed only off-bouts between civil dawn (04:33-05:09) and civil dusk (20:34-21:08) between 26 April 2015 and 18 May 2015 (see Table 1). Day length varied in our study period between $15 \mathrm{~h} 25 \mathrm{~min}$ (26 April) and $16 \mathrm{~h} 35 \mathrm{~min}$ (18 May).

\section{Statistical analyses}

We performed preliminary tests to study if incubation behavior differs during the 8 days of incubation using a non-parametric Kruskal-Wallis test. To understand the relationship between weather conditions and female incubation behavior (number of off-bouts per day, $N=99$ days), we ran a generalized linear mixed effect model (GLMM). Before analyzing data, variables were tested for the assumption of normality and for multicollinearity. Since the spread in the response variable was large and indicated overdispersion, we fitted a negative binomial GLMM. We included daily average of local ambient temperature and sum of regional precipitation (calculated between civil dawn and dusk) and their interaction, day of incubation (incubation day 1-8) and total clutch volume as explanatory variables. Body mass of females correlated with total clutch volume (see results) and was, therefore, not included in the GLMM. In addition, clutch size was excluded from the analysis, because it highly correlated with clutch volume (see results). Nest box ID was used as random effect.

Then, we ran a binomial GLMM to assess the effect of weather conditions on the probability, that females either took an off-bout or stayed within the nest box (nest attendance $N=396$ ). To account for diurnal changes in incubation behavior, four diurnal periods were considered: early morning (from civil dawn until 6:59), forenoon (from 7:00 until 11:59), afternoon (12:00-16:59) and evening (17:00 until civil dusk). We calculated average local ambient temperature and average amount of regional precipitation throughout the four diurnal periods, and included both parameters and their interaction in the GLMM. In addition, we used day of incubation, diurnal period of day and their interaction, and 
total clutch volume as explanatory variables. Nest box ID was used as random effect.

Finally, the duration of single off-bouts ( $N=685$ offbouts) was analyzed. We used a gamma GLMM, because the dispersion factor was small, indicating that the spread in the data was large (Zuur et al. 2009). Again, data were not normally distributed, but spread in the response was large and indicated overdispersion. Average local ambient temperature during single off-bouts, time of day (minutes after civil dawn) and their interaction term, day of incubation (incubation day 1-8) and total clutch volume were included to analyze variation in the duration of single offbouts. Again, nest box ID was used as random effect.

We independently generated for each of the three response variables (number of off-bouts, nest attendance, duration of off-bouts) a global model including all parameters and employed a multimodel inference approach (Burnham and Anderson 2002) to determine the most important variables. Therefore, we generated a set of models with all possible combinations of fixed effects [R package MuMIn, Bartoń (2018)] and graded models according to their Akaike's information criterion with a correction for small sample sizes $\left(\mathrm{AIC}_{\mathrm{c}}\right)$. Finally, a subset of models with $\Delta \mathrm{AIC}_{\mathrm{c}}$ of less than 2 was obtained and model-averaged coefficients for the subset were extracted. Since Akaike weights of best models were below 0.9 (see results, Table 2) and therefore high model selection uncertainty existed, fullmodel averaging was used (Grueber et al. 2011; Symonds and Moussalli 2011). Upper and lower bounds of the 95\% confidence intervals were calculated for each parameter. Statistical analyses were conducted using the software $\mathrm{R}$ 3.4.1 (R Development Core Team 2008).

\section{Results}

\section{Descriptive statistics}

Clutches were completed between 26 April 2015 and 11 May 2015. Clutch size of the 13 females varied between 7 and 13 eggs (mean \pm SD $10.2 \pm 1.74$ eggs). Average total egg volume per clutch was $16.92 \pm 2.53 \mathrm{~mm}^{3}$ (range $12.3-20.8 \mathrm{~mm}^{3}$ ). Total clutch volume was positively correlated with female body mass (Pearson correlation, $t=3.398$, $d f=11, P=0.006, r=0.716)$ and with clutch size (Pearson correlation, $t=7.764, d f=11, P<0.001, r=0.920)$. Date of first egg did not affect clutch size (Pearson correlation, $t=-0.185, d f=11, P=0.856, r=-0.056)$. Therefore, we assume that, date of first egg should also not affect incubation behavior, since clutch initiation of all 13 studied nests laid within a short period of 17 days (between 14 April and 1 May 2015).

\section{Variables affecting incubation behavior of females}

Females performed their first off-bout per day in the morning $148.1 \pm 189.76$ min (mean \pm SD) after dawn. Average number of off-bouts per day $(6.92 \pm 6.73$, Fig. 2a) and duration of off-bouts (16.93 \pm 25.56 , Fig. $2 b)$ varied among the 13 incubating females. Number of off-bouts was not affected by the stage of incubation (Kruskal-Wallis rank sum test, Chi-squared $=1.53, d f=7, P=0.981$, Fig. 2c). Within the first 8 days of incubation, single off-bouts were longer in the first 3 days of incubation than later on (Kruskal-Wallis rank sum test, Chi-squared $=146.96, d f=7, P<0.001$, Fig. $2 d$ ).

Table 2 Subset of generalized linear mixed effect models explaining variation in female incubation behavior in Great Tits $\left(\Delta \mathrm{AIC} \mathrm{c}_{\mathrm{c}}<2\right) \mathrm{derived}$ using the dredge function (Bartoń 2018)

\begin{tabular}{|c|c|c|c|c|}
\hline Response & Models & $\mathrm{AIC}_{\mathrm{c}}$ & $\Delta \mathrm{AIC}_{\mathrm{c}}$ & $\mathrm{AIC}_{\mathrm{c}}$ weight \\
\hline \multirow[t]{4}{*}{ Number of off-bouts per day } & $=\beta_{0}+$ ambient temp & 552.34 & 0.00 & 0.38 \\
\hline & $=\beta_{0}+$ ambient temp + day of incubation & 553.20 & 0.86 & 0.25 \\
\hline & $=\beta_{0}+$ ambient temp + total clutch volume & 553.57 & 1.23 & 0.21 \\
\hline & $=\beta_{0}+$ ambient temp + precipitation & 554.02 & 1.68 & 0.16 \\
\hline \multirow[t]{8}{*}{ Nest attendance $(0 / 1)$} & $=\beta_{0}+$ ambient temp + diurnal period + total clutch volume & 399.99 & 0.00 & 0.17 \\
\hline & $=\beta_{0}+$ ambient temp + diurnal period & 400.06 & 0.07 & 0.17 \\
\hline & $=\beta_{0}+$ ambient temp + diurnal period + total clutch volume + day of incubation & 400.41 & 0.42 & 0.14 \\
\hline & $=\beta_{0}+$ ambient temp + diurnal period + day of incubation & 400.47 & 0.48 & 0.13 \\
\hline & $=\beta_{0}+$ ambient temp + diurnal period + total clutch volume + precipitation & 400.86 & 0.87 & 0.11 \\
\hline & $=\beta_{0}+$ ambient temp + diurnal period + precipitation & 400.93 & 0.94 & 0.11 \\
\hline & $\begin{aligned}= & \beta_{0}+\text { ambient temp }+ \text { diurnal period }+ \text { total clutch volume }+ \text { day of incuba- } \\
& \text { tion }+ \text { precipitation }\end{aligned}$ & 401.35 & 1.36 & 0.09 \\
\hline & $=\beta_{0}+$ ambient temp + diurnal period + day of incubation + precipitation & 401.41 & 1.42 & 0.08 \\
\hline \multirow[t]{2}{*}{ Duration of off-bouts (min) } & $=\beta_{0}+$ ambient temp*time of day + day of incubation & 4793.95 & 0.00 & 0.68 \\
\hline & $=\beta_{0}+$ ambient temp $*$ time of day + day of incubation + total clutch volume & 4795.41 & 1.46 & 0.32 \\
\hline
\end{tabular}



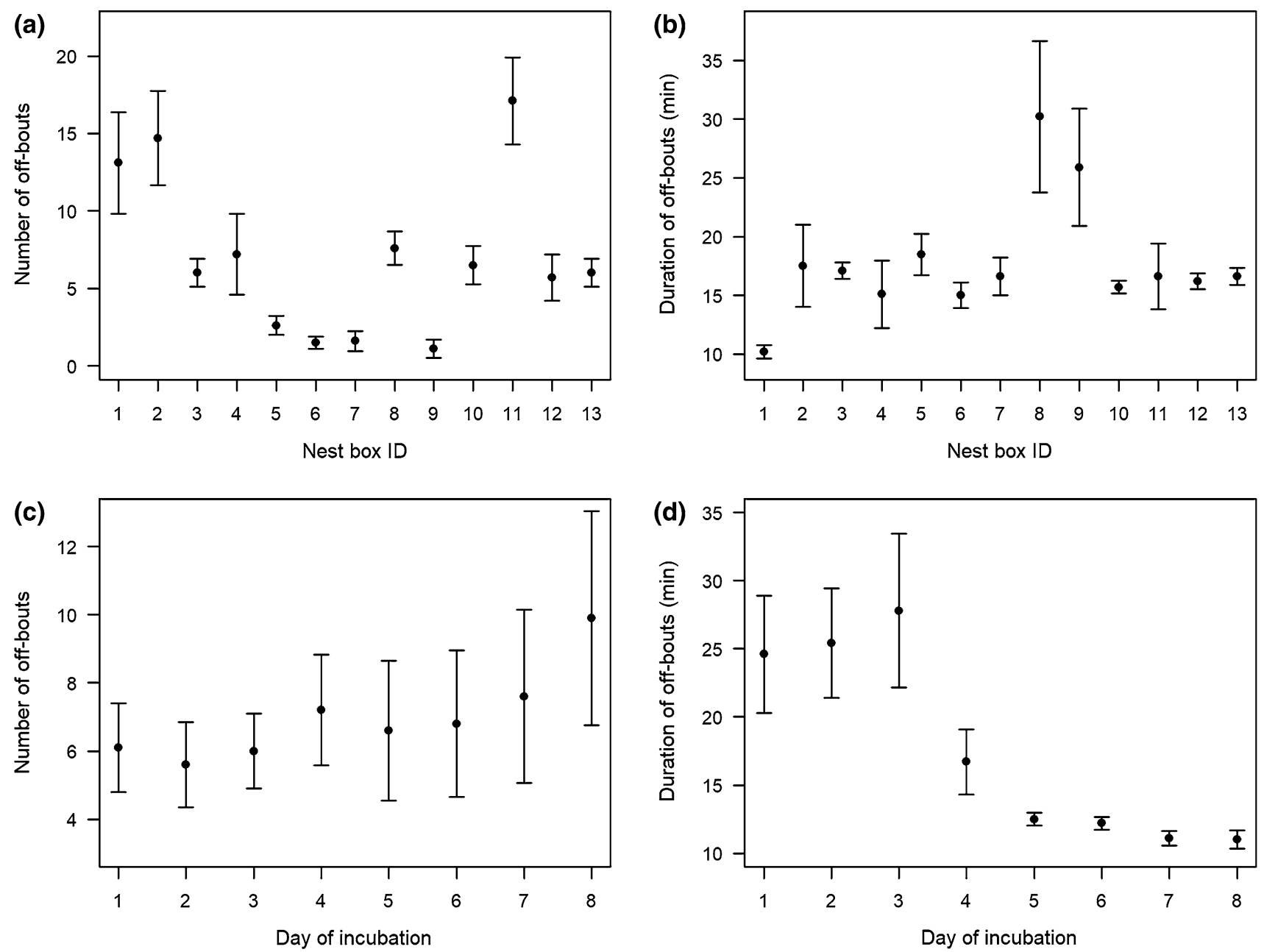

Fig. 2 Incubation behavior (mean \pm SE) of 13 female Great Tits. a Number of off-bouts and $\mathbf{b}$ duration of off-bouts per nest box and $\mathbf{c}$ number of off-bouts and $\mathbf{d}$ duration of off-bouts throughout the incubation period

For modeling the number of off-bouts per day, the subset of models with $\Delta \mathrm{AIC}_{\mathrm{c}}<2$ encompassed 4 models (Table 2). The final model describing number of off-bouts per day included the variables mean local ambient temperature and sum of regional precipitation per day (calculated between civil dawn and dusk), day of incubation and total clutch volume. Number of off-bouts per day decreased with increasing local ambient temperature. Confidence intervals for the parameter estimates of regional precipitation, day of incubation and total clutch volume included zero and importance values were below 0.5 , indicating little evidence that these variables affected the daily number of off-bouts (Table 3 ).

The subset of models explaining variation in the probability that females either took an off-bout or stayed within the nest box (nest attendance) encompassed 8 models (Table 2). The final model included the variables mean local ambient temperature throughout the four diurnal periods, mean amount of regional precipitation throughout the four diurnal periods, day of incubation, diurnal period of the day and total clutch volume. The probability of females incubating their clutch increased with increasing local ambient temperature. Confidence intervals for the parameters estimates of precipitation, day of incubation and total clutch volume indicated little evidence of them affecting the probability of females staying or leaving nest boxes (Table 3 ).

For modeling duration of off-bouts, the subset encompassed 2 models (Table 2). The final model describing duration of single off-bouts included the variables average local ambient temperature during off-bouts, time of day and their interaction term, day of incubation and total clutch volume. Duration of single off-bouts was negatively affected by local ambient temperature, time of day and stage of incubation. Confidence intervals for the parameter estimate of total clutch volume included zero, indicating little evidence that this predictor is associated with duration of single off-bouts (Table 3 ). 
Table 3 Summary statistics after model averaging

\begin{tabular}{|c|c|c|c|c|c|}
\hline Response & Variables & Estimate & Unconditional SE & Confidence intervals & $\begin{array}{l}\text { Relative } \\
\text { importance }\end{array}$ \\
\hline \multirow[t]{5}{*}{ Number of off-bouts per day } & (Intercept) & 3.3829 & 1.07190 & $1.265,5.501$ & \\
\hline & Ambient temp & -0.1058 & 0.02841 & $-0.162,-0.049$ & 1.00 \\
\hline & Day of incubation & 0.0405 & 0.03431 & $-0.028,0.109$ & 0.25 \\
\hline & Total clutch volume & -0.0959 & 0.09488 & $-0.284,0.092$ & 0.21 \\
\hline & precipitation & -0.0122 & 0.01663 & $-0.045,0.021$ & 0.16 \\
\hline \multirow[t]{9}{*}{ Nest attendance $(0 / 1)$} & (Intercept) & -5.6422 & 3.23825 & $-11.999,0.715$ & \\
\hline & Ambient temp & 0.2187 & 0.04734 & $0.126,0.312$ & 1.00 \\
\hline & Diurnal period & & & & 1.00 \\
\hline & Forenoon & -1.1531 & 0.40102 & $-1.942,-0.365$ & \\
\hline & Afternoon & -1.4318 & 0.46081 & $-2.336,-0.526$ & \\
\hline & Evening & -0.8810 & 0.40633 & $-1.680,-0.082$ & \\
\hline & Total clutch volume & 0.2676 & 0.17838 & $-0.083,0.618$ & 0.51 \\
\hline & Day of incubation & 0.0830 & 0.06493 & $-0.045,0.211$ & 0.45 \\
\hline & precipitation & 1.3361 & 1.22796 & $-1.079,3.750$ & 0.39 \\
\hline \multirow[t]{6}{*}{ Duration of off-bouts (min) } & (Intercept) & 4.3480 & 0.33410 & $3.692,5.003$ & \\
\hline & Ambient temp & -0.0520 & 0.01278 & $-0.077,-0.027$ & 1.00 \\
\hline & time of day & -0.0016 & 0.00029 & $-0.002,-0.001$ & 1.00 \\
\hline & Day of incubation & -0.1480 & 0.01086 & $-0.169,-0.127$ & 1.00 \\
\hline & Total clutch volume & -0.0200 & 0.02567 & $-0.070,0.030$ & 0.32 \\
\hline & Ambient temp*time of day & 0.0001 & 0.00002 & $0.00005,0.0001$ & 1.00 \\
\hline
\end{tabular}

Estimates of coefficients and unconditional standard error (SE) and upper and lower 95\% confidence intervals for the subset of models with $\Delta \mathrm{AIC}_{\mathrm{c}}<2$. Important parameters affecting response variables are highlighted in bold

\section{Discussion}

Here, we investigated the influence of diurnal weather conditions on the incubation behavior of female Great Tits. Daily number and duration of off-bouts were negatively associated with local ambient temperature, which varied throughout the day. Our findings highlight that diurnal patterns in ambient temperature can explain variation in incubation behavior.

In our study site, not only average regional ambient temperatures between dawn and dusk, but also maximum regional daily temperatures were below the appropriate temperature of $36-40{ }^{\circ} \mathrm{C}$ which is necessary for optimal embryo development (DuRant et al. 2013). Thus, eggs cooled down when females left nest boxes. Regional temperature was lowest during early morning and rose until late afternoon before it decreased again (see Fig. 1a). Since rewarming eggs is energetically costly (Vleck 1981), especially if ambient temperature is low (Biebach 1986), we assumed that time of day should also affect incubation rhythms (but see also Álvarez and Barba 2014c). We showed, that local ambient temperature and time of day affected duration of single offbouts and nest attendance of females. Contrary to our expectations, female Great Tits made more frequent and longer off-bouts when local ambient temperatures were low (but see Cresswell and McCleery 2003; Simmonds et al. 2017). The probability that females stayed in the nest box increased with increasing local ambient temperature. Eggs were exposed to low local ambient temperatures especially during the early morning, when females spent more time outside nest boxes (see also Kluijver 1950; Prinzinger 1978) to forage ( see Moiron et al. 2018). In contrast, Bueno-Enciso et al. (2017) found that nest attentiveness increased with decreasing ambient temperature, indicating that female great and blue tits adapted their incubation behavior to ambient temperature. The studies of Álvarez and Barba (2014a) on Great Tits and Amininasab et al. (2016) on Blue Tits (Cyanistes caeruleus) showed a positive effect of ambient temperature on off-bout duration, but both variables were measured at a coarser temporal resolution than in our study. To relate ambient temperature to the length of off-bouts, they used averaged daily temperature values measured between sunrise and sunset (Amininasab et al. 2016), or across 10-h periods (Álvarez and Barba 2014a). Averaging ambient temperature over a prolonged period of at least $10 \mathrm{~h}$ /day does not capture the fine-scaled variation in temperature early in the morning and throughout the day. Therefore, the relationship between ambient temperature and off-bout duration they found is probably associated with phenology patterns. Our analyses, however, focused on diurnal patterns. This is a likely explanation for the differing results of our study and the other 
investigations. Fine temporal and spatial resolution temperature data are necessary to study diurnal cycles in detail. Foraging during the early morning might be necessary to ensure self-maintenance (Moiron et al. 2018); thus, energetic constraints might be the major driver of incubation behavior in our population. Conway and Martin (2000a) showed that off-bouts were less correlated with ambient temperature in the early morning, indicating that females tried to optimize foraging bouts. If part of the energy needed to rewarm eggs after an off-bout is a by-product of heat generated during flights (Biebach 1986), females will at least compensate for increasing energy requirements to heat eggs during low temperatures. It could possibly be even advantageous to take a long off-bout in the morning to forage, if food is highly available. Then, energy intake could outcompete costs of rewarming eggs and the energy budget might not be negatively affected by off-bouts during low-temperature periods.

Great Tits are relatively small birds, and therefore, ratio of surface area to volume is high and they quickly lose heat. To avoid hypothermia, they have to increase their energy expenditure, especially if their feathers are wet (Wilson et al. 2004). Hence, staying inside the nest box during short periods of precipitation should be advantageous (see also Skutch 1962; Coe et al. 2015). Although the variable regional precipitation was included in our final models regarding number of daily off-bouts and nest attendance, we found no clear evidence that it affected incubation behavior. In our study site, regional precipitation was more common in the afternoon, which is the period of daytime when ambient temperature is usually the highest. Diurnal temperature cycles affected incubation behavior and thus, local temperature seems to be a stronger predictor than regional precipitation.

Similar to studies on Great Tits (Álvarez and Barba 2014c; Basso and Richner 2015) and Black-capped Chickadees (Poecile atricapillus) (Cooper and Voss 2013), our results showed that the stage of incubation, and therefore the age of the embryo are associated with incubation behavior. Thus, female Great Tits made shorter off-bouts as incubation progressed. They seemed to compensate for increasing egg cooling rates in late stages of incubation (Cooper and Voss 2013) by spending only short periods off the nest. However, as females did not compensate for shorter off-bout durations by increasing the number of off-bouts, they spent more time in the nest box as incubation progressed. Contrary results were found in the study of Conway and Martin (2000b), which covered 97 North American passerines. They showed that off-bout duration is not only negatively related to the number of off-bouts, but also positively affected by ambient temperature at breeding locations (shrub, ground, canopy, cavity). Increasing time spent in the nest boxes as incubation progressed might also be associated with an increasing food availability in the late stage of incubation in our study site.
High food availability might allow females to spend less time outside nest boxes to search for food (Londoño et al. 2008; but see Conway and Martin 2000b). Increasing time spent in the nest box negatively affects total duration of incubation periods (Martin et al. 2007). Thus, high food availability during incubation period might affect hatching date of nestlings. Indeed, female Great Tits seem to adjust their incubation behavior, and thereby breeding success, by varying clutch size and/or onset of incubation to synchronize the hatching of nestlings with a peak of food abundance (Cresswell and McCleery 2003; Simmonds et al. 2017).

We also analyzed, if incubation behavior during early stages of incubation (between day 1 and 8 of incubation) is affected by clutch size, since cooling of eggs is dependent on the surface area-volume ratio. Cooling of small clutches is faster than cooling of large clutches (Reid et al. 2000; Cooper and Voss 2013). Thus, females should leave their small clutches only for a short time period, to avoid rapidly cooling of the eggs, but could instead increase number of offbouts (Reid et al. 2000; Boulton and Cassey 2012; Cooper and Voss 2013). In our study, total clutch volume was not associated with duration of single off-bouts and number of daily off-bouts within the first 8 days of incubation.

Nevertheless, three points have to be kept in mind when interpreting these data. The findings of our study on incubation behavior of Great Tits should be interpreted with caution, because (1) the sample size of 13 nests, which were studied within a single breeding season, was small. Therefore, the power of detecting differences in incubation behavior was rather low; (2) only the first 8 days of incubation after clutch completion were studied and not the whole period, which usually lasts for 12-15 days (Glutz von Blotzheim and Bauer 1993). In addition, incubation can already begin after the penultimate egg is laid (Haftorn 1981) and (3) we did not collect data on male incubation feeding, which seems to be related to ambient temperature and might affect incubation behavior (Amininasab et al. 2016, 2017; Bambini et al. 2019).

In conclusion, we showed that low local ambient temperatures during mornings did not result in an avoidance of off-bouts, although low temperatures should be disadvantageous for energy management during incubation. Since food intake is of particular importance to balance energy demands for self-maintenance, foraging in the early morning seems to outcompete energy requirements during these cold temperature periods. Although diurnal patterns in regional precipitation existed, precipitation did not affect incubation behavior in our study area. However, we would expect that intensity and duration of precipitation could affect incubation patterns, but a fine temporal and spatial resolution of precipitation data is necessary to study this phenomenon in more detail. 
Acknowledgements Open access funding provided by University of Natural Resources and Life Sciences Vienna (BOKU). This study was funded by the Federal Ministry for Sustainability and Tourism, Austria; Wolfgang Pauli Fellowship, University of Vienna and the Austrian Federal Forests. Permission to handle our study animals was given by the Office of the Provincial Government of Lower Austria. The Austrian Federal Forests gave their permission to work on their land. We thank an anonymous reviewer who provided helpful comments on an earlier draft.

Open Access This article is distributed under the terms of the Creative Commons Attribution 4.0 International License (http://creativeco mmons.org/licenses/by/4.0/), which permits unrestricted use, distribution, and reproduction in any medium, provided you give appropriate credit to the original author(s) and the source, provide a link to the Creative Commons license, and indicate if changes were made.

\section{References}

Álvarez E, Barba E (2014a) Behavioural responses of great tits to experimental manipulation of nest temperature during incubation. Ornis Fenn 91:220-230

Álvarez E, Barba E (2014b) Incubation and hatching periods in a Mediterranean great tit Parus major population. Bird Study 61:152161. https://doi.org/10.1080/00063657.2014.908819

Álvarez E, Barba E (2014c) Within and between population variations of incubation rhythm of great tits Parus major. Behaviour 151:1827-1845. https://doi.org/10.1163/1568539X-00003218

Amininasab SM, Kingma SA, Birker M, Hildenbrandt H, Komdeur J (2016) The effect of ambient temperature, habitat quality and individual age on incubation behaviour and incubation feeding in a socially monogamous songbird. Behav Ecol Sociobiol 70:15911600. https://doi.org/10.1007/s00265-016-2167-2

Amininasab SM, Birker M, Kingma SA, Hildenbrandt H, Komdeur $\mathrm{J}$ (2017) The effect of male incubation feeding on female nest attendance and reproductive performance in a socially monogamous bird. J Ornithol 158:687-696. https://doi.org/10.1007/s1033 6-016-1427-2

Bambini G, Schlicht E, Kempenaers B (2019) Patterns of female nest attendance and male feeding throughout the incubation period in blue tits Cyanistes caeruleus. Ibis 161:50-65. https://doi. org/10.1111/ibi.12614

Bartoń K (2018) MuMIn: Multi-Model Inference. R package version 1.40 .4

Basso A, Richner H (2015) Predator-specific effects on incubation behaviour and offspring growth in great tits. PLoS One 10:e121088. https://doi.org/10.1371/journal.pone.0121088

Biebach H (1986) Energetics of rewarming a clutch in Starlings (Sturnus vulgaris). Physiol Zool 59:69-75

Boulton RL, Cassey P (2012) How avian incubation behaviour influences egg surface temperatures: relationships with egg position, development and clutch size. J Avian Biol 43:289-296. https:// doi.org/10.1111/j.1600-048X.2012.05657.x

Boulton RL, Richard Y, Armstrong DP (2010) The effect of male incubation feeding, food and temperature on the incubation behaviour of New Zealand Robins. Ethology 116:490-497. https://doi.org/1 0.1111/j.1439-0310.2010.01759.x

Bueno-Enciso J, Barrientos R, Sanz JJ (2017) Incubation behaviour of blue Cyanistes caeruleus and great tits Parus major in a Mediterranean habitat. Acta Ornithol 52:21-34. https://doi. org/10.3161/00016454ao2017.52.1.003

Burnham KP, Anderson DR (2002) Model selection and multimodel inference: a practical information-theoretic approach. Springer, New York
Coe BH, Beck ML, Chin SY, Jachowski CMB, Hopkins WA (2015) Local variation in weather conditions influences incubation behavior and temperature in a passerine bird. J Avian Biol 46:385-394. https://doi.org/10.1111/jav.00581

Conway CJ, Martin TE (2000a) Effects of ambient temperature on avian incubation behavior. Behav Ecol 11:178-188

Conway CJ, Martin TE (2000b) Evolution of passerine incubation behavior: influence of food, temperature, and nest predation. Evolution 54:670-685

Cooper CB, Mills H (2005) New software for quantifying incubation behavior from time-series recordings. J Field Ornithol 76:352-356

Cooper CB, Voss MA (2013) Avian incubation patterns reflect temporal changes in developing clutches. PLoS One 8:e65521. https ://doi.org/10.1371/journal.pone.0065521

Cresswell W, McCleery R (2003) How great tits maintain synchronization of their hatch date with food supply in response to long-term variability in temperature. J Anim Ecol 72:356-366. https://doi.org/10.1046/j.1365-2656.2003.00701.x

Dai A, Lin X, Hsu K-L (2007) The frequency, intensity, and diurnal cycle of precipitation in surface and satellite observations over low- and mid-latitudes. Clim Dyn 29:727-744. https://doi. org/10.1007/s00382-007-0260-y

Deeming DC (2002) Behaviour patterns during incubation. In: Deeming DC (ed) Avian incubation: behaviour, environment, and evolution. Oxford University Press, Oxford, pp 63-87

Drent R (1975) Incubation. In: Farner DS, King JR (eds) Avian biology. Academic Press, New York, pp 333-420

Durant SE, Hopkins WA, Hepp GR, Walters JR (2013) Ecological, evolutionary, and conservation implications of incubation temperature-dependent phenotypes in birds. Biol Rev 88:499-509. https://doi.org/10.1111/brv.12015

Glutz Von Blotzheim UN, Bauer KM (1993) Handbuch der Vögel Mitteleuropas. Aula-Verlag, Wiesbaden

Grueber CE, Nakagawa S, Laws RJ, Jamieson IG (2011) Multimodel inference in ecology and evolution: challenges and solutions. J Evol Biol 24:699-711. https://doi.org/10.111 $1 / \mathrm{j} .1420-9101.2010 .02210 . \mathrm{x}$

Haftorn S (1981) Incubation during the egg-laying period in relation to clutch-size and other aspects of reproduction in the great tit Parus major. Ornis Scand 12:169-185

Hansell MH, Deeming DC (2002) Location, structure and function of incubation sites. In: Deeming DC (ed) Avian incubation: behaviour, environment, and evolution. Oxford University Press, Oxford, pp 8-27

Joyce EM, Sillett TS, Holmes RT (2001) An inexpensive method for quantifying incubation patterns of open-cup nesting birds, with data for black-throated blue warblers. J Field Ornithol 72:369379. https://doi.org/10.1648/0273-8570-72.3.369

Kluijver HN (1950) Daily routines of the great tit Parus m. major L. Ardea 38:99-135. https://doi.org/10.5253/arde.v38.p99

Kovařík P, Pavel V, Chutný B (2009) Incubation behaviour of the Meadow Pipit (Anthus pratensis) in an alpine ecosystem of Central Europe. J Ornithol 150:549-556. https://doi.org/10.1007/ s10336-009-0380-8

Londoño GA, Levey DJ, Robinson SK (2008) Effects of temperature and food on incubation behaviour of the Northern Mockingbird, Mimus polyglottos. Anim Behav 76:669-677. https://doi. org/10.1016/j.anbehav.2008.05.002

Martin TE, Auer SK, Bassar RD, Niklison AM, Lloyd P (2007) Geographic variation in avian incubation periods and parental influences on embryonic temperature. Evolution 61:2558-2569. https://doi.org/10.1111/j.1558-5646.2007.00204.x

Martin TE, Boyce AJ, Fierro-Calderón K, Mitchell AE, Armstad CE, Mouton JC, Bin Soudi EE, Gremillet D (2017) Enclosed nests may provide greater thermal than nest predation benefits 
compared with open nests across latitudes. Funct Ecol 31:12311240. https://doi.org/10.1111/1365-2435.12819

Moiron M, Mathot KJ, Dingemanse NJ (2018) To eat and not be eaten: diurnal mass gain and foraging strategies in wintering great tits. Proc R Soc Lond B Biol. https://doi.org/10.1098/ rspb.2017.2868

Perrins CM (1965) Population fluctuations and clutch-size in the great tit, Parus major L. J Anim Ecol 34:601-647. https://doi. org/10.2307/2453

Prinzinger R (1978) Freilanduntersuchungen zur Regulation einiger Bebrütungs-Parameter bei der Kohlmeise (Parus major). J Ornithol 119:116-118. https://doi.org/10.1007/BF01642980

R Development Core Team (2008) R: a language and environment for statistical computing. R Foundation for Statistical Computing, Vienna

Reid JM, Monaghan P, Ruxton GD (2000) The consequences of clutch size for incubation conditions and hatching success in starlings. Funct Ecol 14:560-565. https://doi.org/10.104 6/j.1365-2435.2000.00446.x

Reid JM, Monaghan P, Nager RG (2002) Incubation and the costs of reproduction. In: Deeming DC (ed) Avian incubation: behaviour, environment, and evolution. Oxford University Press, Oxford, pp 314-325

Simmonds EG, Sheldon BC, Coulson T, Cole EF (2017) Incubation behavior adjustments, driven by ambient temperature variation, improve synchrony between hatch dates and caterpillar peak in a wild bird population. Ecol Evol 7:9415-9425. https://doi. org/10.1002/ece3.3446

Skutch AF (1962) The constancy of incubation. Wilson Bull $74: 115-152$

Stenning MJ (2008) Hatching asynchrony and brood reduction in blue tits Cyanistes caeruleus may be a plastic response to local oak Quercus robur bud burst and caterpillar emergence. Acta Ornithol 43:97-106. https://doi.org/10.3161/000164508×345383
Symonds MRE, Moussalli A (2011) A brief guide to model selection, multimodel inference and model averaging in behavioural ecology using Akaike's information criterion. Behav Ecol Sociobiol 65:13-21. https://doi.org/10.1007/s00265-010-1037-6

Tatum JB (1975) Egg volume. Auk 92:576-580

Thomson DL, Monaghan P, Furness RW (1998) The demands of incubation and avian clutch size. Biol Rev 73:293-304. https://doi. org/10.1017/S0006323198005180

Vleck CM (1981) Energetic costs of incubation in the Zebra finch. Condor 83:229-237

Wesolowski T, Czeszczewik D, Rowiński P, Walankiewicz W (2002) Nest soaking in natural holes-a serious cause of breeding failure? Ornis Fenn 79:132-138

Williams JB (1996) Energetics of avian incubation. In: Carey C (ed) Avian energetics and nutritional ecology. Springer US, Boston, pp 375-415

Wilson GR, Cooper SJ, Gessaman JA (2004) The effects of temperature and artificial rain on the metabolism of American Kestrels (Falco sparverius). Comp Biochem Phys A 139:389-394. https ://doi.org/10.1016/j.cbpb.2004.10.009

Yaqub A, Seibert P, Formayer H (2010) Diurnal precipitation cycle in Austria. Theor Appl Climatol 103:109-118. https://doi. org/10.1007/s00704-010-0281-z

Zuur AF, Ieno EN, Walker NJ, Saveliev AA, Smith GM (2009) Mixed effects models and extensions in ecology with R. Springer, New York

Publisher's Note Springer Nature remains neutral with regard to jurisdictional claims in published maps and institutional affiliations. 